\title{
Demonstration of serum monoclonal im
in a case of non-secretory myeloma by immunoisoelectric focusing
}

\author{
T SHEEHAN, ${ }^{*}$ D SINCLAIR, $\dagger$ P TANSEY,${ }^{*}$ JR O' DONNELL ${ }^{*}$ \\ From the *Department of Haematology, Victoria Infirmary, Glasgow, and the $†$ Department of Immunology, \\ Western Infirmary, Glasgow
}

SUMMARY A paraprotein band in non-secretory myeloma was shown using a highly sensitive technique of immunoisoelectric focusing. The published work concerning non-secretory myeloma is briefly reviewed.

Non-secretory myeloma is a rare variant of multiple myeloma in which conventional agarose zonal and immunoelectrophoretic techniques fail to show a paraprotein in either serum or urine. We describe a case in which the highly sensitive technique of immunoisoelectric focusing showed a small $\mathrm{IgG \kappa}$ monoclonal band in the patient's serum and discuss the implications of this finding.

\section{Case report}

A 54 year old woman presented in September 1982 with a one year history of exertional dyspnoea, a three month history of pain in the left hip, and spontaneous bruising of the limbs of recent onset. There was pallor and extensive bruising on both lower limbs, but no lymphadenopathy, hepatosplenomegaly, or sternal tenderness. Her haemoglobin concentration was $5.6 \mathrm{~g} / \mathrm{dl}$, white cell count $3.7 \times 10^{9} / \mathrm{l}$, and platelet count $171.0 \times 10^{9} / 1$. The blood film was leucoerythroblastic with $36 \%$ blast cells and the erythrocyte sedimentation rate was $83 \mathrm{~mm}$ in the first hour. A marrow aspirate showed almost total replacement by primitive cells resembling lymphoblasts (Fig. 1); however, Sudan black, periodic acid Schiff, acid phosphatase, chloracetate esterase, and non-specific esterase stains were all negative. Radiological skeletal survey showed lytic lesions in the right fifth rib, left ischium, and both proximal femora. Ultrasound examination of the abdomen showed no lymphadenopathy or organomegaly. Protein electrophoresis performed on a cellulose monoacetate strip was negative, as was agarose zonal electrophoresis and immunoelectrophoresis. There was

Accepted for publication 16 January 1985 no Bence Jones proteinuria. There was hypogammaglobulinaemia with an $\operatorname{IgA}$ concentration of $0.4 \mathrm{~g} / \mathrm{l}, \mathrm{IgG} 5.4 \mathrm{~g} / \mathrm{l}$, and $\mathrm{IgM} 0.2 \mathrm{~g} / \mathrm{l}$ (normal $0.9-$ $4 \cdot 5 \mathrm{~g} / 1,8-18 \mathrm{~g} / 1$, and $0 \cdot 7-2 \cdot 8 \mathrm{~g} / \mathrm{l})$.

A provisional diagnosis of acute undifferentiated leukaemia was made and chemotherapy comprising daunorubicin, vincristine, and Prednisolone was started. After one pulse of chemotherapy $20 \%$ plasma cells were found in the peripheral blood and a repeat marrow aspirate showed the typical morphological features of myeloma (Fig. 2).

Repeat zonal agarose electrophoresis and $\bar{T}$ immunoelectrophoresis were negative and, again, no Bence Jones proteinuria was found. Immunoperoxidase studies of both bone marrow aspirates showed a monoclonal $\kappa$ light chain staining pattern with a complete absence of demonstrable heavy chain production (Fig. 3). Immunoisoelectric focusing ${ }^{12}$ performed on a blood sample taken after the first pulse of chemotherapy showed a small concentration of monoclonal IgGK (Fig. 4). In view of this finding the immunoperoxidase studies were repeated after trypsinisation of the marrow sections $N$ and monoclonal IgG and $\kappa$ chains were clearly shown in most of the malignant cells (Fig. 5).

Six pulses of combination chemotherapy according to the $\mathbf{M}_{2}$ protocol $^{3}$ were given, but marrow toxicity was unacceptably severe and treatment was $O$ changed to intravenous cyclophosphamide $\left(1 \mathrm{~g} / \mathrm{m}^{2}\right)$ at three weekly intervals. The serum paraprotein remained demonstrable but cannot currently be quantitated by immunoisoelectric focusing. The symptomatic response, however, was dramatic and 13 months after diagnosis the patient remains well and free from bone pain. 


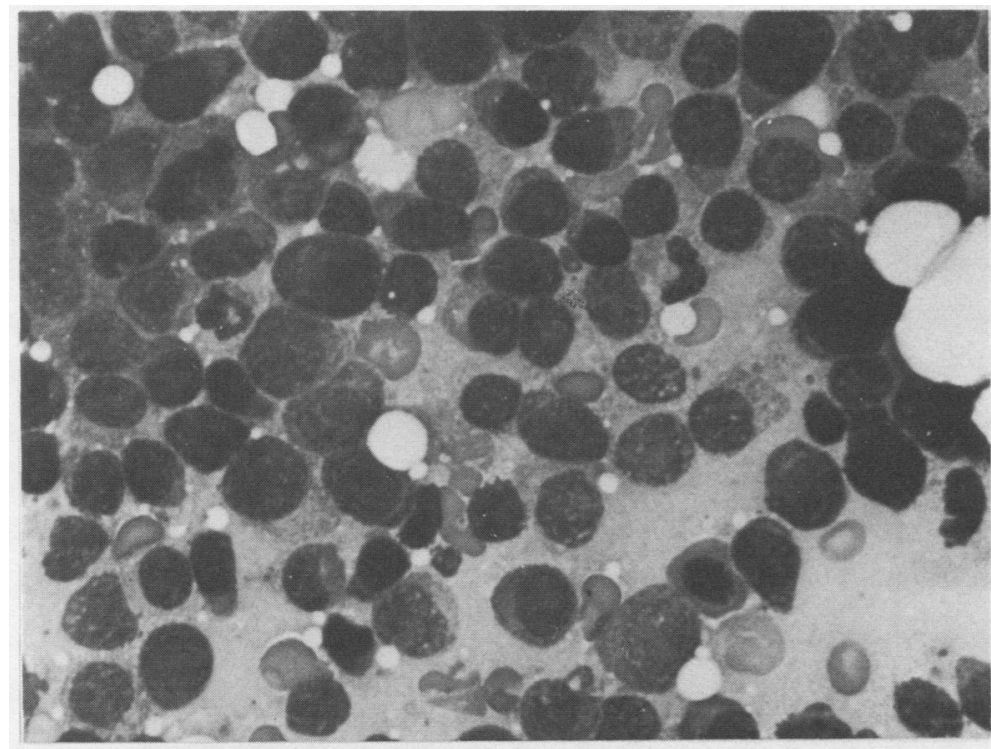

Fig. 1 Marrow appearances at presentation showing numerous immature cells resembling lymphoblasts. $\times 800$.

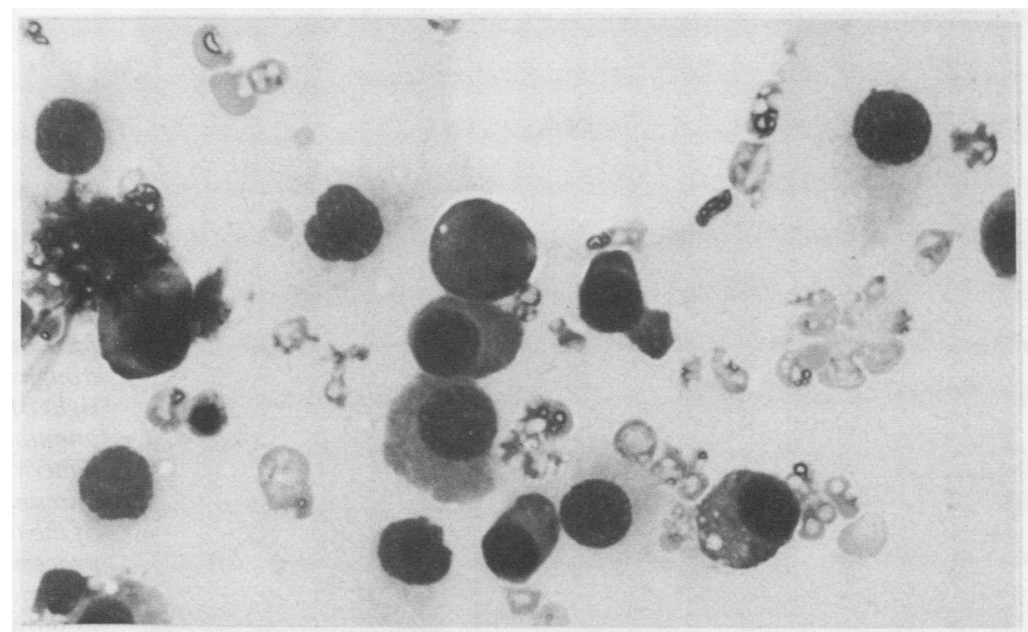

Fig. 2 Marrow appearances after chemotherapy showing typical morphological features of myeloma. $\times 800$.

\section{Discussion}

In about $1-2 \%$ of cases of multiple myeloma conventional zonal and immunoelectrophoretic techniques fail to show a paraprotein band in either serum or urine. ${ }^{45}$ Such non-secretory variants of myeloma seem to be unusually aggressive, with a reported median survival of seven and a half months in one series. $^{6}$ The generally poor prognosis of nonsecretory myeloma has been confirmed by other authors. ${ }^{57-9}$ The absence of a detectable paraprotein in such cases also makes the monitoring of response to treatment more difficult.

Hobbs ${ }^{7}$ suggested that zonal and immunoelectrophoresis will detect a paraprotein in myeloma only when at least $20 \mathrm{~g}$ of tumour is present. Isoelectric focusing seems to be the most sensitive method available for showing the microheterogeneity or homogeneity of proteins, and when combined with immunofixation it may identify small paraprotein 


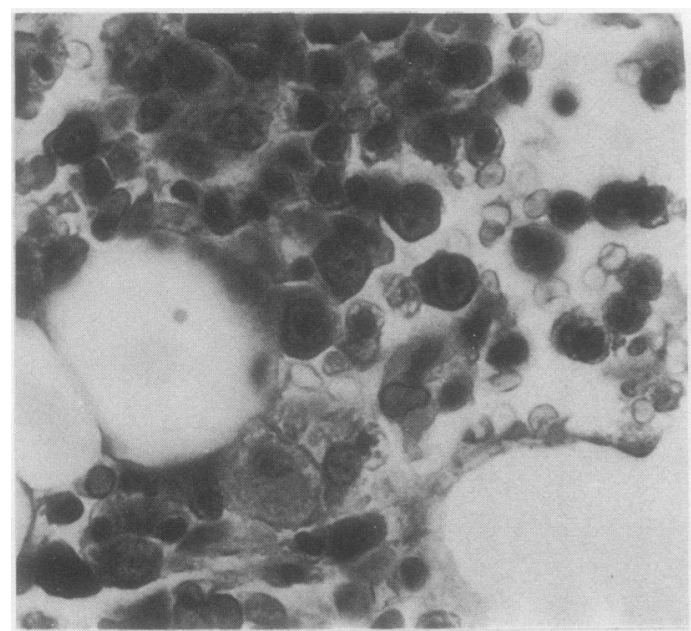

Fig. 3 Marrow stained with immunoperoxidase showing a number of cells (arrows) staining positively with anti- $\kappa . \times$ 800.

N

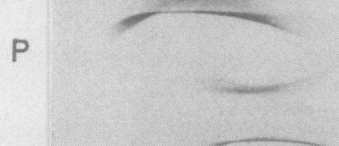

$\mathrm{N}$

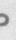

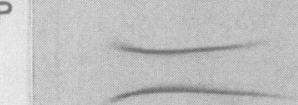

N

$P$

N

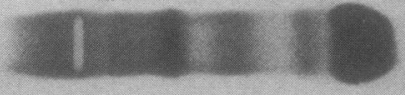

P

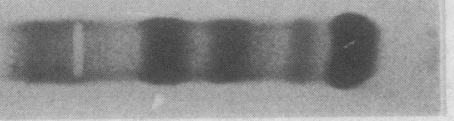

IEP 
immunoisoelectric focusing

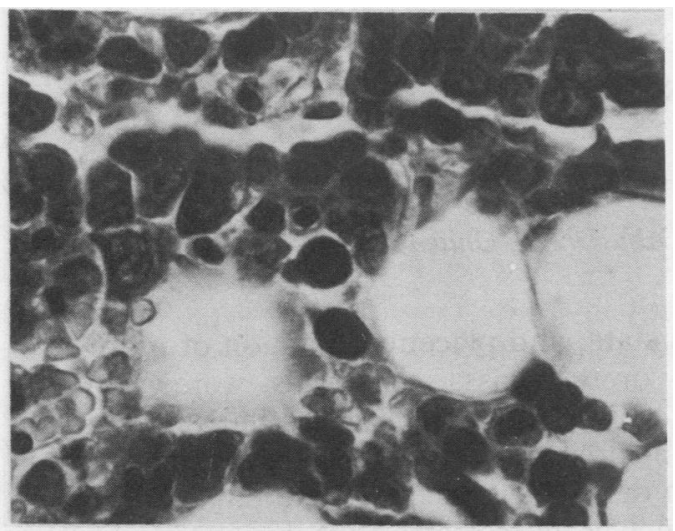

Fig. 5 Trypsinised marrow sections stained with immunoperoxidase showing a number of cells (arrows) staining positively with anti-IgG. $\times 800$.

bands when conventional techiques have failed, as in the present case.'

The explanation for the absence of detectable paraprotein in rare cases of myeloma has been the subject of considerable debate. In some cases intracellular immunoglobulin has been shown by immunofluorescence, ${ }^{10} 11$ implying a defect in immunoglobulin secretion rather than production, while in others no intracellular immunoglobulin was found. $^{811}$ Putham and Miyake suggested ${ }^{12}$ that the malignant cells in some cases either manufacture no immunoglobulin or produce an aberrant immunoglobulin not detectable using conventional antisera

The finding of amyloidosis in one case of nonsecretory myeloma raises the possibility that in some cases the malignant cells may secrete immunoglobulin in quantities too small to be detected by conventional techniques. ${ }^{6}$ In vitro secretion of small quantities of immunoglobulin has recently been shown in a case of non-secretory myeloma. ${ }^{13}$ While we are unable to prove conclusively that the paraprotein in the case reported here represents the secretory product of the malignant cells, the presence of intracellular immunoglobulin of identical heavy and light chain type strongly supports this contention. Further studies which may clarify this point, entailing the use of idiotypic antisera, are underway.

A report by Cereda et $\mathrm{l}^{14}$ highlights one of the problems associated with non-secretory myeloma, in which, by definition, a serum or urinary paraprotein cannot be identified. In their case an erroneous diagnosis of breast carcinoma was made partly on the basis that biochemical markers of myeloma were absent; an $\operatorname{IgA} \lambda$ paraprotein was eventually identified using conventional techniques. Treatment for myeloma was then started, but the patient became profoundly neutropenic and died. It is possible that immunoisoelectric focusing could provide a prompt and definitive diagnosis of multiple myeloma in such difficult cases.

The detection of a small quantity of serum paraprotein in a case of non-secretory myeloma raises important questions about the biology of this disease and highlights the potential value of immunoisoelectric focusing as a diagnostic aid. We hope that with the development of reliable quantitative methods this highly sensitive technique will find a place in the biochemical monitoring of response to treatment.

\section{References}

' Sinclair D, Kumaratne DS, Forrester JB, Lamont A, Stott DI. The application of isoelectric focusing to routine screening for paraproteinaemia. J Immunol Methods 1983;64:147-56.

${ }^{2}$ Sinclair D, Kumaratne DS, Stott DI. The detection and identification of serum monoclonal immunoglobulin by immunoisoelectric focusing. Limits of sensitivity and use during relapse of multiple myeloma. J Clin Pathol 1984;37:25562.

${ }^{3}$ Case DC, Lee BJ, Clarkson BD. Improved survival times in multiple myeloma treated with melphelan, prednisolone, cyclophosphamide, vincristine, and BCNU: M2 protocol. Am J Med 1977;63:897-903.

4 Osserman EF, Takatsuki K. Plasma cell myeloma: gamma globulin synthesis and structure. Medicine 1963;42:375-84.

${ }^{5}$ Hobbs JR. Immunochemical classes of myelomatosis. $\mathrm{Br} \mathrm{J}$ Haematol 1969; 16:599-606.

- Azar HA. Non-secretory plasma cell myeloma. Am J Clin Pathol 1972;58:618-29.

' Hobbs JR. Immunocytoma O'Mice an' Men. Br Med J 1971;ii: 67-72.

${ }^{8}$ River GL, Tewksbury DA, Fundenberg HH. Non-secretory multiple myeloma. Blood 1972;40:204-6.

' Bartolini C, Flamini G, Logroscino C, et al. Non-secretory multiple myeloma: report of a case. Blood 1980;56:898-901.

${ }^{10}$ Hurez D, Preud'homme JL, Seligmann M. Intracellular monoclonal immunoglobulin in non-secretory human myeloma. J Immunol 1970;104:263-4.

"Joyner MV, et al. Non-secretory multiple myeloma. $\mathrm{Br} J$ Haematol 1979; 43:559-66.

12 Putham FW, Miyake A. Proteins in multiple myeloma. Biosynthesis of abnormal proteins. J Biol Chem 1958;231:671.

${ }^{13}$ Mabry RJ, Shelburne J, Cohen HJ. In vitro kinetics of immunoglobulin synthesis and secretion of non-secretory human myeloma cells. Blood 1977;50:1031-8.

${ }^{14}$ Cereda JM, Ayres J, Gibson T. Non-excretory myeloma. Br Med J 1982; 285:715-6.

Requests for reprints to: Dr T Sheehan, Department of Haematology, The Victoria Infirmary, Glasgow G42 9TY, Scotland. 